\title{
Traffic-related air pollution in relation to respiratory symptoms, allergic sensitisation and lung function in schoolchildren
}

\author{
M Rosenlund, ${ }^{1,2,3}$ F Forastiere, ${ }^{1}$ D Porta, ${ }^{1}$ M De Sario, ${ }^{1}$ C Badaloni, ${ }^{1}$ C A Perucci ${ }^{1}$
}

${ }^{1}$ Department of Epidemiology, Rome E Local Health Authority, Rome, Italy: ${ }^{2}$ Institute of Environmental Medicine, Karolinska Institutet, Sweden; ${ }^{3}$ Department of Occupational and Environmental Health, Stockholm County Council, Sweden

Correspondence to:

Dr F Forastiere, Department of Epidemiology, Rome E Local Health Authority, Via di S

Costanza 53, 00198 Rome, Italy; forastiere@asplazio.it

Received 18 December 2007 Accepted 29 September 2008 Published Online First

13 October 2008

\begin{abstract}
Background: Urban air pollution can trigger asthma exacerbations, but the effects of long-term exposure to traffic-related air pollution on lung function or onset of airway disease and allergic sensitisation in children is less clear.
\end{abstract}

Methods: All 2107 children aged 9-14 years from 40 schools in Rome in 2000-1 were included in a crosssectional survey. Respiratory symptoms were assessed on 1760 children by parental questionnaires (response rate $83.5 \%$ ). Allergic sensitisation was measured by skin prick tests and lung function was measured by spirometry on 1359 children (77.2\%). Three indicators of trafficrelated air pollution exposure were assessed: selfreported heavy traffic outside the child's home; the measured distance between the child's home and busy roads; and the residential nitrogen dioxide $\left(\mathrm{NO}_{2}\right)$ levels estimated by a land use regression model $\left(R^{2}=0.69\right)$.

Results: There was a strong association between estimated $\mathrm{NO}_{2}$ exposure per $10 \mu \mathrm{g} / \mathrm{m}^{3}$ and lung function, especially expiratory flows, in linear regression models adjusted for age, gender, height and weight: $-0.62 \%$ (95\% Cl -1.05 to -0.19$)$ for forced expiratory volume in $1 \mathrm{~s}$ as a percentage of forced vital capacity, $-62 \mathrm{ml} / \mathrm{s}$ (95\% Cl -102 to -21$)$ for forced expiratory flow between $25 \%$ and $75 \%$ of forced vital capacity and $-85 \mathrm{ml} / \mathrm{s}(95 \% \mathrm{Cl}-135$ to -35$)$ for peak expiratory flow. The other two exposure indicators showed similar but weaker associations. The associations appeared stronger in girls, older children, in children of high socioeconomic status and in those exposed to parental smoking. Although lifetime asthma was not an effect modifier, there was a suggestion of a larger effect on lung function in subjects with a positive prick test. Multiple logistic regression models did not suggest a consistent association between traffic-related air pollution exposure and prevalence of respiratory symptoms or allergic sensitisation.

Conclusion: The results of this study suggest that residential traffic-related air pollution exposure is associated with reduced expiratory flows in schoolchildren.

Numerous studies have reported adverse effects of urban air pollution on various aspects of respiratory health in children. ${ }^{1-8}$ Traffic-related air pollution has been associated with asthma exacerbations, ${ }^{8}$ doctordiagnosed asthma ${ }^{910}$ and increased prevalence of asthma symptoms. ${ }^{11}$ There are also studies demonstrating an association between traffic pollution and sensitisation to pollen and outdoor allergens, as well as increased levels of total and specific IgE. ${ }^{2}{ }^{12}$ Data from cross-sectional studies have also suggested that ambient air pollution can affect lung function in 10-year-old children, ${ }^{13-15}$ and recent longitudinal cohort data have shown that pollution from traffic has adverse effects on children's lung development between 10 and 18 years of age. ${ }^{216} 17$ However, other studies have indicated no association between air pollution indicators and respiratory symptoms ${ }^{18}$ or lung function. ${ }^{19}$

Previous studies have assessed long-term exposure to traffic air pollution by self-reported traffic intensity, ${ }^{5}{ }^{14}$ distance to busy roads ${ }^{10}{ }^{14}$ or estimated pollution levels by dispersion or regression modelling, ${ }^{911}$ but no study has yet evaluated in a comparative way all of these indicators of trafficrelated air pollution exposure. There is also a lack of studies that objectively assess both exposure and disease, and few investigations in Europe have used population data in an urban area with large contrasts in air pollution concentrations. In addition, there are few studies on traffic-related air pollution as a causative agent in the initial disease development in young school children. Even if both epidemiological and experimental studies have proposed plausible biological explanations of these effects, there is a great need for more scientific evidence, especially in view of recent cohort data from California linking air pollution to impaired lung development. ${ }^{2} 1617$

The aim of this study was to investigate the association between traffic-related air pollution exposure and objective measurements of lung function by spirometry and atopy by skin prick testing and parental reports of respiratory symptoms in a population-based study of children in Rome, Italy. Three different indicators of traffic pollution were used: self-reported traffic level, distance from busy roads measured by a geographic information system and the residential levels of nitrogen dioxide $\left(\mathrm{NO}_{2}\right)$ estimated by a land use regression model.

\section{METHODS}

\section{Study subjects and assessment of respiratory health}

The children in this study were enrolled for the Italian part of the second phase of the International Study of Asthma and Allergies in Childhood (ISAAC phase 2). ${ }^{20}$ Selection of participants and data collection were therefore performed according to the ISAAC methodology as described elsewhere. ${ }^{21} 22$ Children were selected from public and private primary schools in Rome (and in the small nearby municipality of Fiumicino). Parents of all children attending the fifth grade during the 2000-1 school year $(n=2107)$ from each school 
$(n=40)$ were contacted. Of these, 1760 (83.5\%) parents of children between 9 and 14 years old responded to the Italian version of the ISAAC II questionnaire.

The standardised questionnaire was used to ascertain lifetime prevalence of asthma, wheeze, hay fever and eczema as well as the child's respiratory health during the past 12 months including wheezing, cough, phlegm and rhinitis. ${ }^{21}$ On the basis of asthma and wheezing onset and the presence of wheezing in the 12 months before the survey (current wheezing) from questionnaire data, children were divided into four mutually exclusive groups: (1) those with asthma or wheezing onset in the first 2 years of life and no current wheezing (early transient wheezers); (2) those with asthma or wheezing onset in the first 2 years of life who still wheezed at the time of the survey (persistent wheezers); (3) those with asthma or wheezing onset from 3 years onwards who still wheezed at the time of the survey (late onset wheezers); (4) those with no wheezing nor asthma in the first two years of life and no current wheezing (control group).

The Italian questionnaire also included certain factors known to be related with asthma and allergies, in particular those that occurred during pregnancy and the postnatal period. In addition, the questionnaire also included items on the intensity of traffic and the frequency of heavy traffic outside the child's home. The parents or another person responsible for the child's care completed the questionnaire.

The parents of each child were informed of the study and provided their consent regarding the health examination, including prick tests and spirometry at school. Informed consent was given by the parents of 1359 children (77.2\%). Prick tests were performed to provide an objective measure of atopic sensitisation to Dermatophagoides pteronyssinus, Dermatophagoides farinae, cat fur, mixed grass pollen, mixed tree pollen and Alternaria tenuis using histamine $(10 \mathrm{mg} / \mathrm{ml})$ and a saline solution as positive and negative controls. In addition, Olea and Parietaria species were included. All extracts and control solutions were obtained from ALK Laboratories (Horsholm, Denmark). Subjects with one or more positive result were considered atopic, determined by a weal size $>3 \mathrm{~mm}^{2}$ from markers on $\mathrm{mm}^{2}$ paper transferred by tape 15 min after exposure. Height, weight and baseline pulmonary function were measured using a portable spirometer (BiomedinPadua, Italy). ${ }^{21}$ The spirometric values for the best blow of at least three attempts were used, according to American Thoracic Society recommendations. ${ }^{23}$ Children with any respiratory infection during the week before the lung function test were excluded. Lung function parameters measured included forced vital capacity (FVC, $\mathrm{ml})$, forced expiratory volume in $1 \mathrm{~s}\left(\mathrm{FEV}_{1}\right.$, $\mathrm{ml}$ ), forced expiratory flow between $25 \%$ and $75 \%$ of FVC $\left(\mathrm{FEF}_{25-75}, \mathrm{ml} / \mathrm{s}\right)$ and peak expiratory flow $(\mathrm{PEF}, \mathrm{ml} / \mathrm{s})$. The best FVC and best $\mathrm{FEV}_{1}$ were recorded, whereas $\mathrm{FEF}_{25-75}$ and PEF were derived from the best curve, defined as the greatest sum of FVC and $\mathrm{FEV}_{1}$. In addition, $\mathrm{FEV}_{1}$ as a percentage of FVC was calculated.

\section{Exposure assessment}

Different indicators of residential traffic-related air pollution were assessed for each child: self-reported traffic intensity and frequency of heavy traffic in the area of residence, the distance from home to busy roads and the estimated $\mathrm{NO}_{2}$ concentrations outside the child's home. Parents of 1732 children (98.4\%) rated traffic intensity as none, little, moderate and heavy, and frequency of heavy traffic as rarely, sometimes or often. A geographical information system (ArcGis 9.1, ESRI, Redlands,
California, USA) was used to geocode the residence of each child at the time of the survey. The Municipal Office of Rome provided information on traffic counts that was used to identify roads with dense traffic. We then estimated the distance from these busy roads for the addresses of 1530 children (86.9\%) and categorised the distances as $>200 \mathrm{~m}, 100-200 \mathrm{~m}, 50-100 \mathrm{~m}$, 20-50 $\mathrm{m}$ and $<20 \mathrm{~m}$ (alternatively as more or less than $100 \mathrm{~m}$ ).

The $\mathrm{NO}_{2}$ concentration in the census block of residence (a small area of about 500 inhabitants per census block) was estimated for each child by a land use regression model described in detail elsewhere. ${ }^{24}$ This model was built by assessing the association between variables describing land use and traffic information and $\mathrm{NO}_{2}$ concentrations measured at 68 sites in Rome. Palme's tubes measured outdoor pollution simultaneously over three 7-day periods in 1995 and 1996. The most important variables predicting measured $\mathrm{NO}_{2}$ were the area of the city, distance from busy roads, size of the census block, inverse population density and altitude, resulting in a determination coefficient $\left(R^{2}\right)$ of 0.686 . A hybrid version of that model was used for the present study where altitude and distance from busy roads were replaced by emission data of benzene obtained from the Municipality of Rome, resulting in an $\mathrm{R}^{2}$ of 0.690 . The correlation between observed and predicted $\mathrm{NO}_{2}$ concentrations from the land use regression model was 0.77. Census blocks with extreme values of input data for the prediction model (ie, inverse population and size of the census block) were excluded to avoid extrapolation of predicted $\mathrm{NO}_{2}$ beyond a reasonable range, resulting in a successful model estimation of residential $\mathrm{NO}_{2}$ concentrations for 1578 (89.7\%) children.

\section{Potential confounders and effect modifiers}

Several potential confounders of the association between trafficrelated air pollution variables and respiratory health were a priori chosen from the questionnaire or from anthropometric measurement: gender, age, height, weight, body mass index (BMI), father's and mother's education (less than high school, high school or above), parental smoking habit (current, former, never smoker), mother smoking during pregnancy (yes, no), parental history of asthma (yes, no), pets during the first year of life (yes, no), keeping a cat or a dog ever (yes, no), day care attendance (yes, no), indoor humidity or signs of mould in the child's bedroom (yes, no), number of siblings and the floor of the subject's home (ground floor, first-second floor, thirdfourth floor, fourth floor or above). We did not take into account gas cooking because 1725 out of 1760 children (95\%) lived in a household using it.

We were also a priori interested in effect modification, in particular whether the air pollution effects differed by gender, age (9-10, 11-14 years), maternal education, current parental smoking as indicator of environmental tobacco smoke (ETS) exposure (no, yes), individual BMI (below and above the 80th percentile), antioxidant intake (fresh fruit consumption $<3$ and $\geqslant 3$ times/week), reported lifetime asthma (no, yes) and atopic status (negative and positive prick test).

\section{Statistical analyses}

Spearman's rank correlation coefficient was used as a nonparametric measure of correlation of the exposure variables. The associations between variables indicating air pollution exposure and lung function parameters were analysed by linear regression. The final multiple linear regression models included only covariates that had a notable impact (10\% change) on the 
Table 1 Descriptive statistics of children living in Rome in 2000-1, separately for those who were clinically tested (lung function and prick tests) and those who were not

\begin{tabular}{|c|c|c|c|c|c|c|}
\hline & \multicolumn{2}{|c|}{ Clinical data $(n=1359)$} & \multicolumn{2}{|c|}{ No clinical data $(n=401)$} & \multicolumn{2}{|c|}{ Total $(n=1760)$} \\
\hline & No & $\%$ & No & $\%$ & No & $\%$ \\
\hline Boys & 711 & 52.3 & 200 & 49.9 & 911 & 51.8 \\
\hline Girls & 648 & 47.7 & 201 & 50.1 & 849 & 48.2 \\
\hline Mean (SD) age (years) & \multicolumn{2}{|c|}{$10.04(0.44)$} & \multicolumn{2}{|c|}{$10.13(0.56)$} & \multicolumn{2}{|c|}{$10.06(0.47)$} \\
\hline Ever wheezing & 227 & 16.7 & 44 & 11.0 & 271 & 15.4 \\
\hline Ever asthma & 194 & 14.3 & 28 & 7.0 & 222 & 12.6 \\
\hline Cough (past 12 months) & 133 & 9.8 & 33 & 8.2 & 166 & 9.4 \\
\hline Phlegm (past 12 months) & 143 & 10.5 & 40 & 10.0 & 183 & 10.4 \\
\hline Symptoms of rhinitis (past 12 months) & 128 & 9.4 & 32 & 8.0 & 160 & 9.1 \\
\hline Mother smoking (current) & 516 & 38.0 & 136 & 33.9 & 652 & 37.0 \\
\hline Father smoking (current) & 612 & 45.0 & 168 & 41.9 & 780 & 44.3 \\
\hline Mother smoked during pregnancy & 155 & 11.4 & 33 & 8.2 & 188 & 10.7 \\
\hline Keeps a dog at home (ever) & 319 & 23.5 & 103 & 25.7 & 422 & 24.0 \\
\hline Keeps a cat at home (ever) & 258 & 19.0 & 68 & 17.0 & 326 & 18.5 \\
\hline Mother with asthma & 89 & 6.5 & 22 & 5.5 & 111 & 6.3 \\
\hline Father with asthma & 107 & 7.9 & 24 & 6.0 & 131 & 7.4 \\
\hline Highly educated mother & 801 & 58.9 & 232 & 57.9 & 1033 & 58.7 \\
\hline Highly educated father & 809 & 59.5 & 223 & 55.6 & 1032 & 58.6 \\
\hline Humidity in child's bedroom* & 170 & 12.5 & 32 & 8.0 & 202 & 11.5 \\
\hline Signs of mould in child's bedroom* & 113 & 8.3 & 24 & 6.0 & 137 & 7.8 \\
\hline Fruit intake more than twice per week & 982 & 72.3 & 287 & 71.6 & 1269 & 72.1 \\
\hline Attended day care & 416 & 30.6 & 116 & 28.9 & 532 & 30.2 \\
\hline No siblings & 227 & 16.7 & 87 & 21.7 & 314 & 17.8 \\
\hline
\end{tabular}

*First year of life.

traffic-related air pollution effect estimates ${ }^{25}$ (ie, age, gender, height and weight). The results are presented as regression coefficients (beta) and 95\% confidence intervals (95\% CI) representing a unit change in the parameter for a $10 \mu \mathrm{g} / \mathrm{m}^{3}$ increase in $\mathrm{NO}_{2}$. For self-reported categorical variables of exposure to traffic and for categories of distance to busy roads, we estimated the change in lung function for each category

Table 2 Descriptive statistics of anthropometric measures, lung function tests and skin prick tests for children who underwent clinical examinations

\begin{tabular}{|c|c|}
\hline \multicolumn{2}{|l|}{ Anthropometric measures $(n=1344)^{*}$} \\
\hline Height $(\mathrm{cm})$ & $144(7)$ \\
\hline Weight (kg) & $41(10)$ \\
\hline \multicolumn{2}{|l|}{ Lung function $(n=1340)^{*}$} \\
\hline $\mathrm{FVC}(\mathrm{ml})$ & $2327(406)$ \\
\hline $\mathrm{FEV}_{1}(\mathrm{ml})$ & $2117(359)$ \\
\hline $\mathrm{FEV}_{1} / \mathrm{FVC}(\%)$ & $91.29(6.65)$ \\
\hline $\mathrm{FEF}_{25-75}(\mathrm{ml} / \mathrm{s})$ & $2716(663)$ \\
\hline $\mathrm{PEF}(\mathrm{ml} / \mathrm{s})$ & $4295(864)$ \\
\hline \multicolumn{2}{|l|}{ Prick tests $(n=1312) \dagger$} \\
\hline Any antigen & $417(31.8 \%)$ \\
\hline Dermatophagoides pteronyssinus & $245(18.7 \%)$ \\
\hline Dermatophagoides farinae & $168(12.8 \%)$ \\
\hline Alternaria tenuis & $108(8.2 \%)$ \\
\hline Cat fur & $107(8.2 \%)$ \\
\hline Mixed grass pollen & $189(14.4 \%)$ \\
\hline Mixed tree pollen & $13(1.0 \%)$ \\
\hline Olea & $161(12.3 \%)$ \\
\hline Parietaria & $54(4.1 \%)$ \\
\hline
\end{tabular}

compared with the first one and the coefficient across the categories to evaluate the linear trend.

The associations between air pollution exposure and respiratory symptoms or atopic sensitisation were analysed by logistic regression and the results are presented as odds ratios (OR) and $95 \%$ confidence intervals $(95 \% \mathrm{CI}$ ). All logistic regression models included covariates that influenced the effect of air pollution by $10 \%$ or more (ie, age, gender, BMI, father's education, maternal smoking, indoor humidity or signs of mould in the child's bedroom, and the floor of the subject's home). The logistic regression analyses were made with an exposure variable representing an interquartile range increase in the $\mathrm{NO}_{2}$ level $\left(14.2 \mu \mathrm{g} / \mathrm{m}^{3}\right.$ ) or dichotomous variables of traffic intensity (nolittle vs moderate-heavy), heavy traffic (rarely vs sometimesoften) and distance to roads (more or less than $100 \mathrm{~m}$ ). Sensitivity analyses were conducted using alternative cut-off points of traffic intensity, heavy traffic and distance to busy roads (at 100,150 or $200 \mathrm{~m}$ ).

Effect modification of the associations between air pollution and respiratory and allergic outcomes was tested by introducing interaction terms in the linear and logistic regression models between $\mathrm{NO}_{2}$ and the a priori considered variables. All statistical analyses were performed with Stata SE Version 9 (Stata, Texas, USA).

\section{RESULTS}

Table 1 shows the general characteristics of the children participating in the study, separately for those who provided clinical and lung function data and for those who did not. The overall prevalence of ever wheezing, asthma and symptoms of rhinitis were $15.4 \%, 12.6 \%$ and $9.1 \%$, respectively. In general, a larger proportion of children who provided clinical data suffered from respiratory symptoms than those who were not clinically tested. Moreover, most of the risk factors related to allergic and airway diseases were more common in the clinically tested group. 
Self-reported traffic intensity

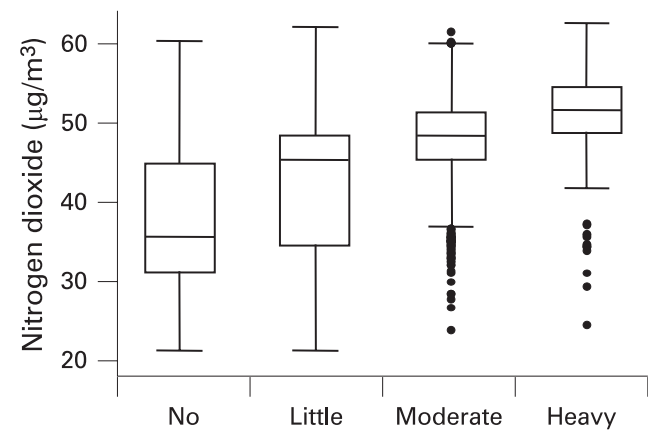

Self-reported frequency of heavy traffic

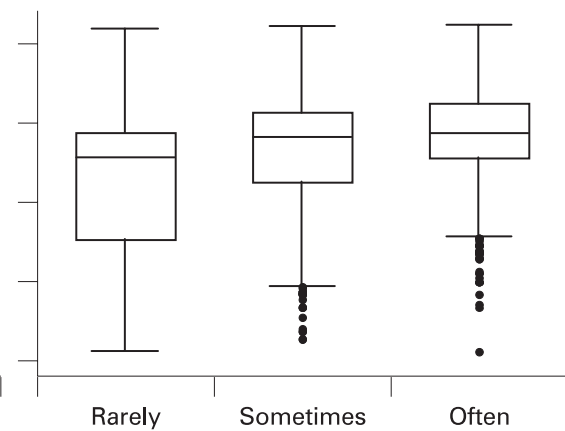

Distance to busy roads

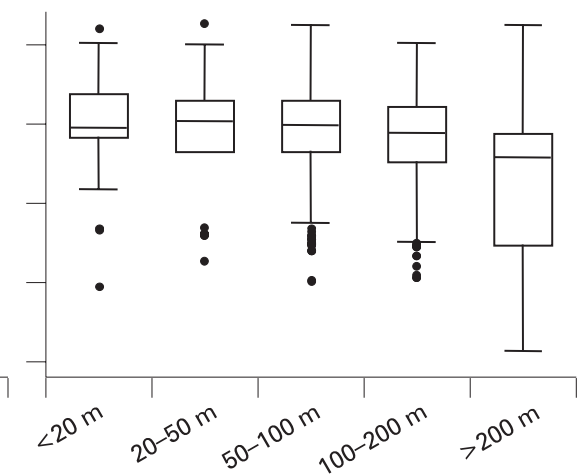

Figure 1 Predicted nitrogen dioxide $\left(\mathrm{NO}_{2}\right)$ exposure according to self-reported residential traffic intensity and distance from busy roads of children in Rome 2000-1. The box includes the 25th (lower hinge) to the 75th (upper hinge) percentile and the median (middle bar), the whiskers represent 1.5 times the interquartile range and the circles are outliers.

Table 2 gives descriptive data of the variables collected at the health examination, including anthropometric measures, lung function parameters and prick test positivity. Almost 32\% showed signs of atopic sensitisation to at least one of the tested allergens. The most frequent was the positivity to $D$ pteronyssinus (18.7\%). In general, boys were more likely than girls to have a positive skin prick test, but the differences were small and not statistically significant (data not shown).

The overall mean individual estimated $\mathrm{NO}_{2}$ exposure was $45 \mu \mathrm{g} / \mathrm{m}^{3}$ (range 21-63 $\mu \mathrm{g} / \mathrm{m}^{3}$ ). The correlation between estimated $\mathrm{NO}_{2}$ exposure and self-reported intensity of traffic outside the child's home was moderate $\left(r_{x y}=0.57\right)$. The mean (and median) estimated air pollution exposure increased with each category of self-reported traffic intensity, from $36.58 \mu \mathrm{g} / \mathrm{m}^{3}$ for those reporting no traffic to $42.13 \mu \mathrm{g} / \mathrm{m}^{3}$ for those with little traffic, $47.36 \mu \mathrm{g} / \mathrm{m}^{3}$ for those with moderate traffic, and up to $51.71 \mu \mathrm{g} / \mathrm{m}^{3}$ for those reporting intense traffic at home (fig 1). The number of children in these categories was 352, 484, 599 and 297, respectively. The self-reported frequency of heavy traffic was less correlated with estimated $\mathrm{NO}_{2}$ $\left(r_{x y}=0.21\right)$ and demonstrated a similar but less pronounced pattern with mean levels from $43.07 \mu \mathrm{g} / \mathrm{m}^{3}$ for those who never or rarely experience heavy traffic to $46.28 \mu \mathrm{g} / \mathrm{m}^{3}$ for those with moderate heavy traffic (a couple of times each day) and $47.74 \mu \mathrm{g} / \mathrm{m}^{3}$ for those who have trucks passing frequently. The number of children in these categories was 962, 563 and 207 , respectively. The estimated $\mathrm{NO}_{2}$ level did not change substantially up to $100 \mathrm{~m}$ away from busy roads, but appeared to decrease with greater distances (fig 1). The mean $\mathrm{NO}_{2}$ level was $50.87 \mu \mathrm{g} / \mathrm{m}^{3}$ within $20 \mathrm{~m}, 48.06 \mu \mathrm{g} / \mathrm{m}^{3} 20-50 \mathrm{~m}$ away, $48.85 \mu \mathrm{g} / \mathrm{m}^{3}$ at $50-100 \mathrm{~m}, 47.62 \mu \mathrm{g} / \mathrm{m}^{3}$ at $100-200 \mathrm{~m}$ and $42.65 \mu \mathrm{g} / \mathrm{m}^{3}$ at $200 \mathrm{~m}$ and more, with 98, 53, 128, 219 and

Table 3 Association between different indicators of residential air pollution exposure and lung function measured in children living in Rome 2000-1, presented as regression coefficients (beta) and 95\% confidence intervals (95\% Cl) from linear regression models adjusted for age, gender, height and weight

\begin{tabular}{|c|c|c|c|c|c|c|}
\hline & \multirow{2}{*}{$\begin{array}{l}\text { No of } \\
\text { subjects }\end{array}$} & \multirow{2}{*}{$\begin{array}{l}\text { FVC (ml) } \\
\text { Beta }(95 \% \mathrm{Cl})\end{array}$} & \multirow{2}{*}{$\begin{array}{l}\text { FEV }_{1}(\mathrm{ml}) \\
\text { Beta }(95 \% \mathrm{Cl})\end{array}$} & \multirow{2}{*}{$\begin{array}{l}\text { FEV }_{1} / \text { FVC (\%) } \\
\text { Beta }(95 \% \mathrm{Cl})\end{array}$} & \multirow{2}{*}{$\begin{array}{l}\text { FEF }_{25-75}(\mathrm{ml} / \mathrm{s}) \\
\text { Beta }(95 \% \mathrm{Cl})\end{array}$} & \multirow{2}{*}{$\begin{array}{l}\text { PEF }(\mathrm{ml} / \mathrm{s}) \\
\text { Beta }(95 \% \mathrm{CI})\end{array}$} \\
\hline & & & & & & \\
\hline $\mathrm{NO}_{2}\left(\right.$ per $\left.10 \mu \mathrm{g} / \mathrm{m}^{3}\right) \dagger$ & 1195 & $1(-18$ to 21$)$ & $-13(-31$ to 5$)$ & $-0.62(-1.05 \text { to }-0.19)^{*}$ & $-62(-102 \text { to }-21)^{*}$ & $-85(-135 \text { to }-35)^{*}$ \\
\hline Traffic intensity: & 1320 & & & & & \\
\hline No (reference) & 273 & 0 & 0 & 0 & 0 & 0 \\
\hline Little & 360 & $-21(-69$ to 27$)$ & $-38(-81$ to 5$)$ & $-0.87(-1.9$ to 0.16$)$ & $-87(-184$ to 11$)$ & $-153(-275 \text { to }-31)^{*}$ \\
\hline Moderate & 458 & $-33(-79$ to 13$)$ & $-38(-79$ to 3$)$ & $-0.37(-1.35$ to 0.61$)$ & $-45(-138$ to 48$)$ & $-180(-297 \text { to }-64)^{* *}$ \\
\hline Heavy & 229 & $-13(-66$ to 41$)$ & $-49(-98 \text { to }-1)^{*}$ & $-1.63(-2.78 \text { to }-0.47)^{* *}$ & $-140(-250 \text { to }-30)^{*}$ & $-246(-383 \text { to }-109)^{* *}$ \\
\hline Test for trend & & $-6(-23$ to 10$)$ & $-14(-29$ to 0$)$ & $-0.4(-0.72 \text { to }-0.02)^{*}$ & $-33(-66.7$ to 0.51$)$ & $-76(-117 \text { to }-34)^{* *}$ \\
\hline Heavy traffic & 1321 & & & & & \\
\hline Rarely (reference) & 743 & 0 & 0 & 0 & 0 & 0 \\
\hline Sometimes & 423 & $33(-3$ to 69$)$ & $13(-20$ to 45$)$ & $-0.69(-1.47$ to 0.09$)$ & $-7(-82$ to 68$)$ & $-16(-109$ to 77$)$ \\
\hline Often & 155 & $70(17 \text { to } 122)^{* *}$ & $34(-13$ to 82$)$ & $-1.21(-2.3 \text { to }-0.07)^{*}$ & $-41(-149$ to 67$)$ & $-73(-208$ to 63$)$ \\
\hline Test for trend & & $34(11 \text { to } 58)^{* *}$ & $16(-5$ to 37$)$ & $-0.6(-1.14 \text { to }-0.12)^{*}$ & $-16(-65$ to 32$)$ & $-30(-91$ to 30$)$ \\
\hline $\begin{array}{l}\text { Distance to busy } \\
\text { roads }(\mathrm{m}) \S\end{array}$ & 1176 & & & & & \\
\hline$\geqslant 200$ (reference) & 788 & 0 & 0 & 0 & 0 & 0 \\
\hline 100-199 & 171 & $46(-4$ to 95$)$ & $61(16 \text { to } 106)^{* *}$ & $0.83(-0.27$ to 1.93$)$ & $97(-7$ to 201$)$ & $115(-13$ to 243$)$ \\
\hline $50-99$ & 97 & $11(-52$ to 75$)$ & $-2(-60$ to 55$)$ & $-0.63(-2.03$ to 0.77$)$ & $-73(-208$ to 62$)$ & $-80(-244$ to 83$)$ \\
\hline $20-49$ & 36 & $13(-87$ to 75$)$ & $46(-45$ to 136$)$ & $1.35(-0.87$ to 3.56$)$ & $80(-130$ to 290$)$ & $-18(-276$ to 83$)$ \\
\hline$\geqslant 20$ & 84 & $76(8 \text { to } 143)^{*}$ & $30(-31$ to 92$)$ & $-1.52(-3.02 \text { to }-0.03)^{*}$ & $-22(-166$ to 121$)$ & $-76(-250$ to 98$)$ \\
\hline Test for trend & & $16(1 \text { to } 30)^{*}$ & $9(-4$ to 22$)$ & $-0.2(-0.53$ to 0.11$)$ & $-2(-33$ to 29$)$ & $-16(-54$ to 21$)$ \\
\hline
\end{tabular}

${ }^{*} \mathrm{p}<0.05,{ }^{* *} \mathrm{p}<0.01$. †Assessed by a land use regression model. $t$ Self-reported traffic intensity. §Objectively estimated on a digital map by the GIS tool ArcGIS.

$\mathrm{FEF}_{25-75}$, forced expiratory flow between $25 \%$ and $75 \%$ of $\mathrm{FVC}$; FEV 1 , forced expiratory volume in $1 \mathrm{~s}$; FVC, forced vital capacity; PEF, peak expiratory flow. 
Table 4 Effect modification of a priori considered variables: regression coefficients (beta) and 95\% confidence intervals $(95 \% \mathrm{Cl}$ ) from stratified linear regression models adjusted for age, gender, height and weight

\begin{tabular}{|c|c|c|c|c|c|}
\hline & \multirow[b]{2}{*}{ No } & \multirow{2}{*}{$\begin{array}{l}\text { FEV }_{1}(\mathrm{ml}) \\
\text { Beta }(95 \% \mathrm{Cl})\end{array}$} & \multirow[b]{2}{*}{ p Value* } & \multirow{2}{*}{$\begin{array}{l}\text { FEF }_{25-75}(\mathrm{ml} / \mathrm{s}) \\
\text { Beta }(95 \% \mathrm{Cl})\end{array}$} & \multirow[b]{2}{*}{ p Value* } \\
\hline & & & & & \\
\hline \multicolumn{6}{|l|}{ Gender } \\
\hline Boys & 711 & $-4(-29$ to 21$)$ & 0.250 & $-26(-81$ to 29$)$ & 0.056 \\
\hline Girls & 648 & $-23(-49$ to 2$)$ & & $-103(-163$ to -43$)$ & \\
\hline \multicolumn{6}{|l|}{ Age (years) } \\
\hline $9-10$ & 1213 & $-6(-25$ to 12$)$ & 0.011 & $-53(-95$ to -11$)$ & 0.014 \\
\hline $11-14$ & 146 & $-89(-154$ to -24$)$ & & $-158(-313$ to -3$)$ & \\
\hline \multicolumn{6}{|l|}{ Maternal education } \\
\hline Low & 538 & $3(-27$ to 33$)$ & 0.208 & $-9(-75$ to 57$)$ & 0.061 \\
\hline High & 801 & $-23(-46$ to 0$)$ & & $-91(-144$ to -38$)$ & \\
\hline \multicolumn{6}{|l|}{ ETS at home } \\
\hline No & 683 & $-13(-38$ to 11$)$ & 0.907 & $-29(-86$ to 29$)$ & 0.080 \\
\hline Yes & 662 & $-13(-39$ to 13$)$ & & $-99(-156$ to -42$)$ & \\
\hline \multicolumn{6}{|l|}{ Fruit intake } \\
\hline 0-2 times/week & 377 & $-5(-41$ to 31$)$ & 0.634 & $-109(-190$ to -28$)$ & 0.188 \\
\hline$>2$ times/week & 982 & $-15(-36$ to 5$)$ & & $-47(-94$ to 1$)$ & \\
\hline \multicolumn{6}{|l|}{$\mathrm{BMI}$} \\
\hline Low-normal & 1489 & $-12(-34$ to 3$)$ & 0.382 & $-57(-99$ to -15$)$ & 0.322 \\
\hline High† & 271 & $16(-57$ to 89$)$ & & $-143(-293$ to 7$)$ & \\
\hline \multicolumn{6}{|l|}{ Asthma } \\
\hline Never & 1152 & $-16(-36$ to 4$)$ & 0.672 & $-67(-113$ to -21$)$ & 0.633 \\
\hline Ever & 194 & $-5(-46$ to 37$)$ & & $-41(-133$ to 52$)$ & \\
\hline \multicolumn{6}{|c|}{ Positivity to prick test } \\
\hline No & 895 & $-13(-34$ to 8$)$ & 0.929 & $-40(-87$ to 8$)$ & 0.112 \\
\hline At least one & 417 & $-14(-49$ to 21$)$ & & $-119(-197$ to -40$)$ & \\
\hline
\end{tabular}

${ }^{*} p$ Value for interaction. $†$ Highest quintile.

$\mathrm{BMI}$, body mass index; ETS, environmental tobacco smoke; $\mathrm{FEF}_{25-75}$, forced expiratory flow between $25 \%$ and $75 \%$ of $\mathrm{FVC}$; $\mathrm{FEV}_{1}$, forced expiratory volume in $1 \mathrm{~s}$; FVC, forced vital capacity.

1032 children, respectively, in each of these categories. The correlation between distance from busy roads and estimated residential $\mathrm{NO}_{2}$ levels was -0.47 .

Traffic-related air pollution exposure estimated as the residential $\mathrm{NO}_{2}$ level by a land use regression model was associated with reduced lung function for all spirometric parameters except FVC (table 3). The effect was statistically significant for the $\mathrm{FEV}_{1} / \mathrm{FVC}$ ratio, $\mathrm{FEF}_{25-75}$ and $\mathrm{PEF}$, with a decrease in lung function measures of $0.62 \%, 62 \mathrm{ml} / \mathrm{s}$ and $85 \mathrm{ml} / \mathrm{s}$ per $10 \mu \mathrm{g} / \mathrm{m}^{3}$ in $\mathrm{NO}_{2}$, respectively. Using self-reported traffic intensity as the relevant exposure presented similar results with a statistically significant negative trend for $\mathrm{FEV}_{1}$ / FVC ratio and PEF. The results for heavy traffic exposure and distance from busy roads were not entirely consistent: heavy traffic appeared to be associated with increasing FVC levels but also with a decrease in the $\mathrm{FEV}_{1} / \mathrm{FVC}$ ratio, while the results for distances to busy roads did not show any significant trend for any of the lung function measures considered, with the exception of FVC.

The results did not change when the analyses were restricted to participants with complete data on all the exposure indices ( $n=1120$, data not shown). When other potential confounders such as maternal and paternal smoking, education level and history of asthma were included in the regression model, the estimated decrease in $\mathrm{FEF}_{25-75}$ related to $\mathrm{NO}_{2}$ changed from $-62 \mathrm{ml} / \mathrm{s}(95 \% \mathrm{CI}-102$ to -21$)$ to $-64 \mathrm{ml} / \mathrm{s}(95 \% \mathrm{CI}-105$ to $-23)$, that is less than $3 \%$, as expected from the strategy chosen in the selection of potential confounders.

In the stratified analyses the effects of $\mathrm{NO}_{2}$ on lung function appeared stronger in girls, older children, those with higher socioeconomic status as indicated by the mother's education, passive smoke exposure and low fruit consumption, while the other covariates did not suggest any effect modification (table 4). However, the only statistically significant effect modification was age for $\mathrm{FEV}_{1}$ and $\mathrm{FEF}_{25-75}$. The effect modification of gender, maternal education and ETS at home was of borderline significance for $\mathrm{FEF}_{25-75}$. It is to be noted that, while the effect of traffic-related deficit in lung function was present in children with and without asthma, subjects with a positive skin prick test had the largest effect.

In general, none of the respiratory symptoms or any of the skin prick tests appeared to be positively associated with any of the traffic-related air pollution exposure metrics (fig 2), with the exception of moderate or high frequency of heavy traffic exposure which was positively associated with persistent wheezing (OR 1.84, 95\% CI 1.01 to 3.36 ) and any positive skin prick test (OR 1.30, 95\% CI 1.00 to 1.70 ) and a distance of $100 \mathrm{~m}$ or less from busy roads presenting a statistically significant positive effect on sensitisation to cat antigens ( $O R$ 1.69 , 95\% CI 1.00 to 2.84). Moreover, there was no effect modification of skin prick test positivity for any of the respiratory symptoms analysed (data not shown). Sensitivity analyses using alternative cut-off points of traffic intensity, heavy traffic and distance to busy roads did not substantially change the results (data not shown).

\section{DISCUSSION}

The results of this study suggest that traffic-related air pollution exposure is associated with reduced lung function, especially expiratory flows, in schoolchildren. These results therefore support recent cohort data in the USA demonstrating that exposure to pollution from traffic has adverse effects on 

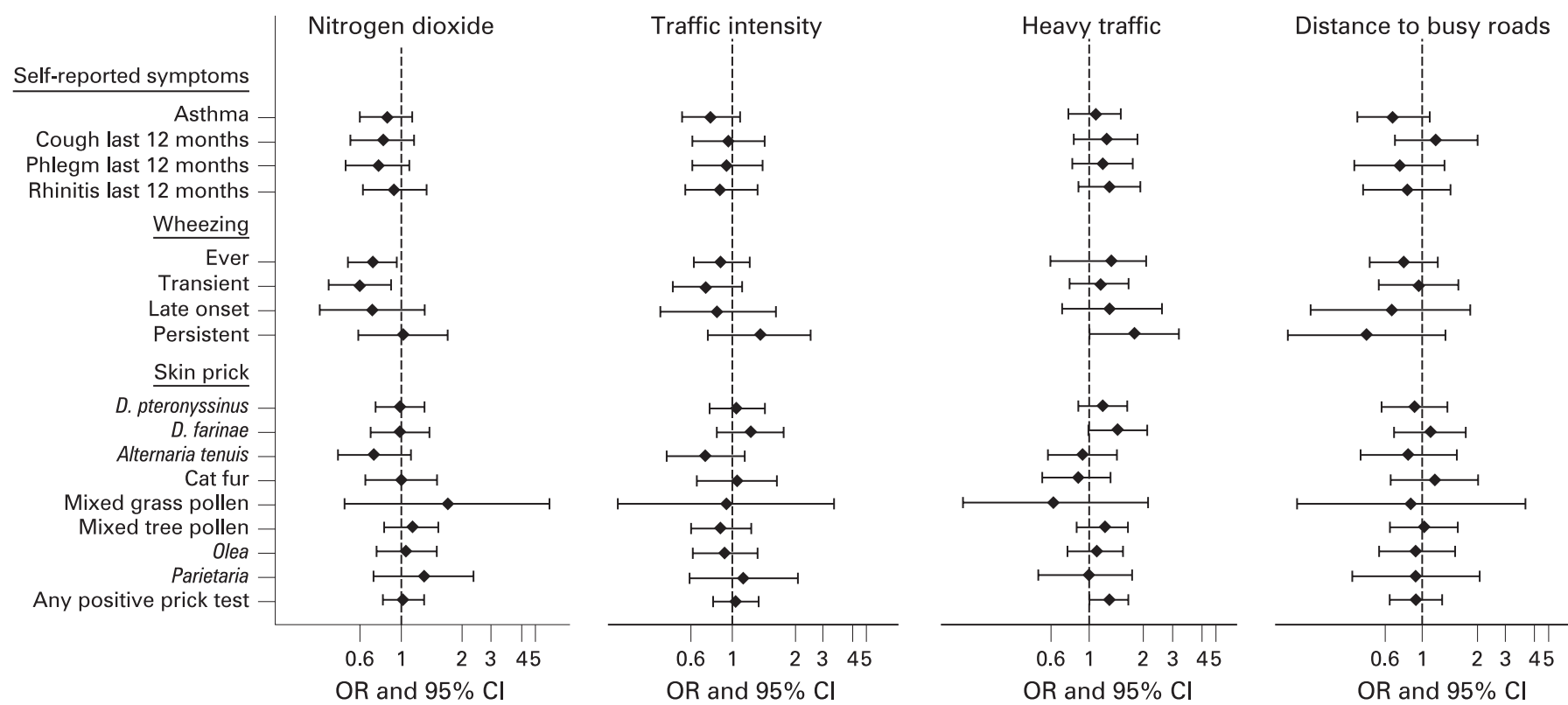

Figure 2 Associations between different indicators of residential air pollution exposure and respiratory symptoms and sensitisation in children living in Rome, 2000-1, presented as odds ratios (OR) and 95\% Cl from logistic regression models (adjusted for age, body mass index, father's education, current mother smoking, indoor humidity or signs of mould during the first year of life and the floor of the subject's home) calculated for an interquartile range increase in the nitrogen dioxide level $\left(14.16 \mu \mathrm{g} / \mathrm{m}^{3}\right)$, dichotomous variables of traffic intensity (no-little vs moderate-heavy), heavy traffic (rarely vs sometimes-often) and distance to roads (more or less than $100 \mathrm{~m}$ ).

children's lung function development. ${ }^{216} 17$ Overall, there was a lack of association between air pollution and respiratory and allergic symptoms which is in agreement with two other studies that used subjective outcome data. ${ }^{18}{ }^{19}$ However, these results are in contrast with many other investigations documenting significant associations between air pollution and objective measures of asthma and allergic sensitisation.

This is the first study on children's respiratory health within a community that includes three different methods to assess long-term traffic-related air pollution exposure, including selfreported traffic, measured distance to busy roads and residential $\mathrm{NO}_{2}$ concentrations estimated by a land use regression model. In addition, three different approaches were applied to assess disease status ranging from subjective questionnaire data on allergic and respiratory symptoms to objective measurements of atopy by skin prick tests and lung function by spirometry.

Several findings of our study deserve consideration. We found that the effect on lung function was stronger and more consistent for the two variables that are more closely related to each other, ie, $\mathrm{NO}_{2}$ from land use regression and self-reported traffic intensity. On the other hand, self-reported heavy traffic and distance to busy roads gave more mixed results. It should be recognised that the indicators are complementary as selfreported traffic level and distance to busy roads measured by the geographic information system take other air pollutants than $\mathrm{NO}_{2}$ into account (eg, fine and ultrafine particles). Our results are consistent with the findings of the Children's Health Effects Study in California where distance from motorways was the exposure variable ${ }^{17}$ and with the recent results from the Oslo Birth Cohort where $\mathrm{NO}_{2}$, particulate matter $\mathrm{PM}_{10}$ and $\mathrm{PM}_{2.5}$ were considered. ${ }^{27}$ We found a similar effect of $\mathrm{NO}_{2}$ on expiratory flow variables that represent peripheral airways, whereas the effect on forced volumes that provide information primarily on damage of the central airways was more limited. Similarly, the recent Swedish birth cohort study found an effect of traffic $\mathrm{PM}_{10}$ and $\mathrm{NO}_{\mathrm{x}}$ on PEF in 4-year-old children. ${ }^{28}$ In addition, our study suggests that the effect of traffic-related air pollution on lung function is not limited to subjects who have asthma, so it is not confined to a well-defined population although there was a tendency for a stronger effect in subjects with atopy.

Some potential weaknesses of this study should be recognised. We used $\mathrm{NO}_{2}$ as an indicator of pollution from traffic because a readily available model for spatial prediction throughout the study region had recently been developed. ${ }^{24}$ However, other components from vehicle exhausts that are more or less correlated with $\mathrm{NO}_{2}$ may be responsible for the observed effects. In this study the $\mathrm{NO}_{2}$ concentration estimated by the regression model appears to be correlated with selfreported traffic intensity outside the children's homes and distance from busy roads. Since exposure was represented by the modelled air pollution levels in the census block where the children lived, some real differences in exposure might have been ignored and consequently the results might be underestimated. In addition, the results were not so much different using traffic intensity as reported by the parents and the measured distance from busy roads as exposure indexes. Although misclassification of true individual exposure levels probably affected the results of this study, the objective assessment of both exposure and disease was done blinded to one another, making such potential bias unlikely to affect the results, except non-differentially.

The present study addressed all schoolchildren in the predefined study area and the high response rate (83.3\%) makes selection bias less likely to seriously affect the results. Nevertheless, the study was a cross-sectional investigation and parents were asked to report their children's lifetime and past year prevalence of allergic and respiratory symptoms. Thus, recall bias and non-differential misclassification of disease from proxy reports may be of concern. On the other hand, this study has several advantages compared with previous investigations, including the three different ways used to assess exposure and 
disease both objectively and subjectively, as well as a geographically well-defined study area with large exposure contrasts.

A slightly stronger effect of $\mathrm{NO}_{2}$ on lung function was suggested in girls than boys, which is supported by earlier evidence showing that girls may be more sensitive to air pollution. ${ }^{26-33}$ Certainly, contrasting evidence exists from recent cohort data, and there can be several reasons for different effects between studies such as different age ranges more or less close to puberty, different air pollution mixtures, different underlying population susceptibilities and different study designs. ${ }^{16}$ Nevertheless, there is a consistency in the findings of air pollution among girls throughout Europe that calls for further investigation of the underlying relevant mechanism. There was an indication of effect modification by other covariates, suggesting stronger effects in older children, in children with higher maternal education and in children whose parents smoked at home. Although the reasons for these differences are not entirely clear, there are some plausible explanations. Older children may have experienced longer cumulative air pollution exposure on average that has affected their lung growth. ${ }^{16}$ Mother's education could be a proxy for socioeconomic status, which might point to higher air pollution exposure on average in Rome for those of a higher socioeconomic status living in the central part of the city. $^{31}$ Finally, exposure to parental smoking at home is a well-established detrimental factor for lung function development that could act synergistically with traffic-related air pollution.

Although the biological mechanisms of how traffic-related air pollution reduces lung function in children are not fully understood, several plausible explanations have been discussed in the literature. Air pollution can induce oxidative stress in the respiratory tract resulting in airway inflammation. ${ }^{31}$ Trafficrelated air pollution has also been correlated with the amount of carbon in the airway macrophages of children which, in turn, was associated with reductions in lung function measured as $\mathrm{FEV}_{1}$ and forced expiratory flows. ${ }^{32}$ Thus, chronic airway inflammation could produce the decreases in lung function measures like those reported in the present study, and the peripheral airways seem to be mainly affected given the stronger signal that we detected for PEF and $\mathrm{FEF}_{25-75}$. However, it is difficult to discuss aetiological mechanisms in the context of a cross-sectional study.

The results of this study slightly differed depending on the exposure indicator used. Although air pollution exposure has been assessed as traffic intensity by others, ${ }^{5}{ }^{14}$ this may be a fairly crude estimate of traffic-related air pollution exposure and especially inappropriate to assess from a questionnaire in relation to subjective symptom reports since subjective measures of both exposure and disease might introduce a correlation of errors. Distance from busy roads appears to be a reasonable proxy for residential air pollution exposure, but it produced different and less consistent results throughout the analyses presented in this study. Despite the weaknesses of the land use regression model, we believe that the predicted $\mathrm{NO}_{2}$ levels produce the most reliable results and that the analyses of linear regression between these levels and lung function parameters should be regarded as the main results of this study.

In conclusion, the results of this study suggest that residential traffic-related air pollution is associated with decreased expiratory lung flows in schoolchildren. However, atopic sensitisation and self-reported respiratory and allergic symptoms were not consistently associated with traffic-related air pollution.
Acknowledgements: The authors thank Riccardo Di Domenicantonio and Patrizia Compagnucci for data collection, Riccardo Pistelli and Sandra Sammarro for clinical evaluation of the children and lung function tests and Margaret Becker for her editorial revision of the manuscript.

Competing interests: None.

Ethics approval: The study was approved by the ethical committee of the Catholic University of Rome.

\section{REFERENCES}

1. Braun-Fahrlander C, Vuille JC, Sennhauser FH, et al. Respiratory health and long term exposure to air pollutants in Swiss schoolchildren. SCARPOL Team. Swiss Study on Childhood Allergy and Respiratory Symptoms with Respect to Air Pollution, Climate and Pollen. Am J Respir Crit Care Med 1997;155:1042-9.

2. Gauderman WJ, Avol E, Gilliland F, et al. The effect of air pollution on lung development from 10 to 18 years of age. N Engl J Med 2004;351:1057-67.

3. Hirsch T, Weiland SK, von Mutius E, et al. Inner city air pollution and respiratory health and atopy in children. Eur Respir J 1999;14:669-77.

4. Schwartz J. Air pollution and children's health. Pediatrics 2004;113(4 Suppl):1037-43

5. Wjst M, Reitmeir P, Dold S, et al. Road traffic and adverse effects on respiratory health in children. BMJ 1993;307:596-600.

6. Heinrich J, Hoelscher B, Wichmann HE. Decline of ambient air pollution and respiratory symptoms in children. Am J Respir Crit Care Med 2000;161:1930-6.

7. Penard-Morand C, Charpin D, Raherison C, et al. Long-term exposure to background air pollution related to respiratory and allergic health in schoolchildren. Clin Exp Allergy 2005;35:1279-87.

8. Schildcrout JS, Sheppard L, Lumley T, et al. Ambient air pollution and asthma exacerbations in children: an eight-city analysis. Am J Epidemiol 2006;164:505-17.

9. Brauer M, Hoek G, Van Vliet P, et al. Air pollution from traffic and the development of respiratory infections and asthmatic and allergic symptoms in children. Am J Respir Crit Care Med 2002;166:1092-8.

10. Shima M, Nitta Y, Adachi M. Traffic-related air pollution and respiratory symptoms in children living along trunk roads in Chiba Prefecture, Japan. J Epidemiol 2003;13:108-19.

11. Morgenstern V, Zutavern A, Cyrys J, et al. Respiratory health and individual estimated exposure to traffic-related air pollutants in a cohort of young children. Occup Environ Med 2007;64:8-16.

12. Kramer U, Koch T, Ranft U, Ring J, et al. Traffic-related air pollution is associated with atopy in children living in urban areas. Epidemiology 2000;11:64-70.

13. Schwartz J. Lung function and chronic exposure to air pollution: a cross-sectional analysis of NHANES II. Environ Res 1989;50:309-21.

14. Brunekreef B, Janssen NA, de Hartog J, et al. Air pollution from truck traffic and lung function in children living near motorways. Epidemiology 1997;8:298-303.

15. Boezen HM, van der Zee SC, Postma DS, et al. Effects of ambient air pollution on upper and lower respiratory symptoms and peak expiratory flow in children. Lancet 1999;353:874-8.

16. Gauderman WJ, Vora H, McConnell R, et al. Effect of exposure to traffic on lung development from 10 to 18 years of age: a cohort study. Lancet 2007; 369:571-7.

17. Gauderman WJ, McConnell R, Gilliland F, et al. Association between air pollution and lung function growth in southern California children. Am J Respir Crit Care Med 2000;162(4 Pt 1):1383-90.

18. Magnus $\mathbf{P}$, Nafstad P, Oie L, et al. Exposure to nitrogen dioxide and the occurrence of bronchial obstruction in children below 2 years. Int $\mathrm{J}$ Epidemiol 1998;27:995-9.

19. Dockery DW, Speizer FE, Stram DO, et al. Effects of inhalable particles on respiratory health of children. Am Rev Respir Dis 1989;139:587-94.

20. International Study of Asthma and Allergies in Childhood (ISAAC) Steering Committee. Worldwide variation in prevalence of symptoms of asthma, allergic rhinoconjunctivitis, and atopic eczema: ISAAC. Lancet 1998;351:1225-32.

21. De Sario M, Di Domenicantonio R, Corbo G, et al. Characteristics of early transient, persistent, and late onset wheezers at 9 to 11 years of age. J Asthma 2006;43:633-8.

22. Weiland SK, Bjorksten B, Brunekreef B, et al. Phase II of the International Study of Asthma and Allergies in Childhood (ISAAC II): rationale and methods. Eur Respir J 2004;24:406-12.

23. American Thoracic Society. Standardisation of spirometry, 1994 update. Am J Respir Crit Care Med 1995;152:1107-36.

24. Rosenlund M, Forastiere F, Stafoggia M, et al. Comparison of regression models with land-use and emissions data to predict the spatial distribution of traffic-related air pollution in Rome. J Expos Sci Environ Epidemiol 2008;18:192-9.

25. Greenland S. Modeling and variable selection in epidemiologic analysis. Am J Public Health 1989;79:340-9.

26. Oftedal B, Brunekreef B, Nystad W, et al. Residential outdoor air pollution and lung function in schoolchildren. Epidemiology 2008;19:129-37.

27. Nordling $\mathbf{E}$, Berglind N, Melén E, et al. Traffic-related air pollution and childhood respiratory symptoms, function and allergies. Epidemiology 2008;19:401-8.

28. Pershagen G, Rylander E, Norberg $\mathrm{S}$, et al. Air pollution involving nitrogen dioxide exposure and wheezing bronchitis in children. Int J Epidemiol 1995:24:1147-53.

29. Neas LM, Dockery DW, Ware JH, et al. Association of indoor nitrogen dioxide with respiratory symptoms and pulmonary function in children. Am J Epidemiol 1991:134:204-19. 
30. McConnell R, Berhane K, Yao L, et al. Traffic, susceptibility, and childhood asthma. Environ Health Perspect 2006;114:766-72.

31. Cesaroni G, Badaloni C, Porta D, et al. Comparison between several indices of exposure to traffic-related air pollution and their respiratory health impact in adults. Occup Environ Med 2008;65:683-90.
32. Li N, Hao M, Phalen RF, Hinds WC, et al. Particulate air pollutants and asthma. A paradigm for the role of oxidative stress in PM-induced adverse health effects. Clin Immunol 2003;109:250-65.

33. Kulkarni N, Pierse N, Rushton L, et al. Carbon in airway macrophages and lung function in children. N Engl J Med 2006;355:21-30.

\section{Beware the pregnant woman with breathlessness}

A 32-year-old woman in the 20th week of her third pregnancy was referred to the advanced lung disease service with breathlessness. As a child she could not keep up with the other children and was told that she had a "hole in the heart" but this did not require further investigation or treatment. In previous pregnancies she had been breathless and fatigued from midtrimester and into the postpartum period, but she thought this was a normal change in pregnancy.

Examination revealed a soft systolic murmur and loud second heart sound. Echocardiography showed an abnormal dilated left atrium, mildly dilated right ventricle and an estimated pulmonary artery systolic pressure of $60 \mathrm{~mm} \mathrm{Hg}$, but no evidence of an atrial septal defect, ventricular septal defect or patent ductus arteriosus. VQ (ventilation-perfusion) scan showed no evidence of thromboembolic disease. Highresolution CT chest excluded interstitial lung disease.

Cardiac MRI (fig 1) revealed an unusual cause for her pulmonary hypertension.

\section{QUESTION}

What is the cause of her pulmonary hypertension?

see page 586 for answer.

This case is submitted by:

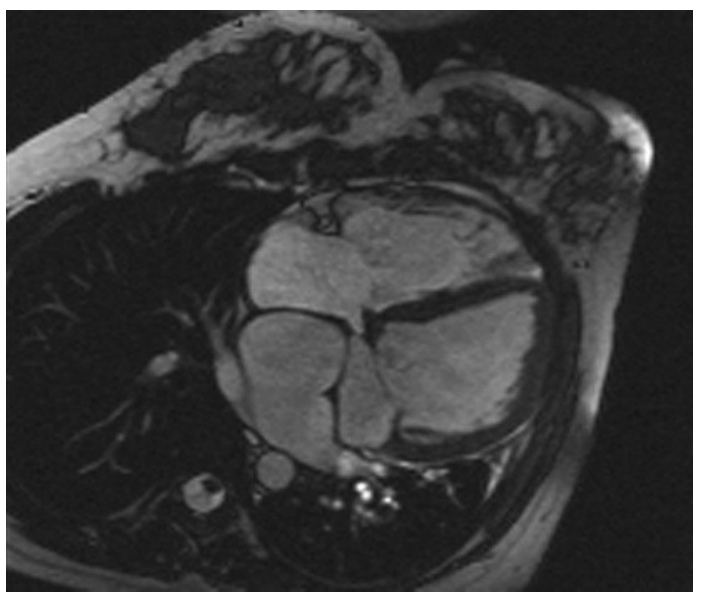

Figure 1 Cardiac MRI-four-chamber view.

\section{A Higton, C Whale, M Musk, E Gabbay}

Advanced Lung Disease Unit, Ainslee House, Royal Perth Hospital, Perth, Western Australia, 6004, Australia

Correspondence to: Dr A Higton, Advanced Lung Disease Unit, Ainslee House, Royal Perth Hospital, Perth, Western Australia,6004, Australia; alexhigton@yahoo.co.uk

Competing interests: None

Patient consent: Obtained.

Thorax 2009;64:580. doi:10.1136/thx.2008.105353 